\title{
Human-animal interactions and safety during dairy cattle handling- Comparing moving cows to milking and hoof trimming
}

\author{
C. Lindahl, ${ }^{*}{ }^{1}$ S. Pinzke, ${ }^{*}$ A. Herlin, $\ddagger$ and L. J. Keeling $\S$ \\ *Department of Work Science, Business Economics and Environmental Psychology, Swedish University of Agricultural Sciences, PO Box 88, \\ SE-230 53, Alnarp, Sweden \\ †Swedish Institute of Agricultural and Environmental Engineering, PO Box 7033, SE-750 07, Uppsala, Sweden \\ ‡Department of Biosystems and Technology, and \\ §Department of Animal Environment and Health, Swedish University of Agricultural Sciences, PO Box 7068, SE-750 07, Uppsala, Sweden
}

\begin{abstract}
Cattle handling is a dangerous activity on dairy farms, and cows are a major cause of injuries to livestock handlers. Even if dairy cows are generally tranquil and docile, when situations occur that they perceive or remember as aversive, they may become agitated and hazardous to handle. This study aimed to compare human-animal interactions, cow behavior, and handler safety when moving cows to daily milking and moving cows to more rarely occurring and possibly aversive hoof trimming. These processes were observed on 12 Swedish commercial dairy farms. The study included behavioral observations of handler and cows and cow heart rate recordings, as well as recording frequencies of situations and incidents related to an increased injury risk to the handler. At milking, cows were quite easily moved using few interactions. As expected, the cows showed no behavioral signs of stress, fear, or resistance and their heart rate only rose slightly from the baseline (i.e., the average heart rate during an undisturbed period before handling). Moving cows to hoof trimming involved more forceful and gentle interactions compared with moving cows to milking. Furthermore, the cows showed much higher frequencies of behaviors indicative of aversion and fear (e.g., freezing, balking, and resistance), as well as a higher increase in heart rate. The risk of injury to which handlers were exposed also increased when moving cows to hoof trimming rather than to routine milking. Some interactions (such as forceful tactile interactions with an object and pulling a neck strap or halter) appeared to be related to potentially dangerous incidents where the handler was being kicked, head-butted, or run over by a cow. In conclusion, moving cows to hoof trimming resulted in higher frequencies of behaviors indicating fear, more
\end{abstract}

Received December 19, 2014.

Accepted November 16, 2015

${ }^{1}$ Corresponding author: Cecilia.Lindahl@jti.se forceful interactions, and increased injury risks to the handler than moving cows to milking. Improving potentially stressful handling procedures (e.g., by better animal handling practices and preparation of cows to cope with such procedures) can increase handler safety, animal welfare, ease of handling, and efficiency.

Key words: injury risk, work safety, moving cattle, claw trimming

\section{INTRODUCTION}

Cattle handling is a dangerous activity on dairy farms (Douphrate et al., 2013), and animals are a major source of injuries to livestock handlers. In a casecontrol study of Dutch farmers' sick leave insurance claims, animals were the major cause of work-related injury among farmers. In a Swedish study, animals were involved in $36 \%$ of the accidental injuries occurring in agriculture and $24 \%$ of the total number of injuries occurring during work with dairy cows (Pinzke and Lundqvist, 2007). American studies have reported animals as the source of 24 to $38 \%$ of total injuries on dairy farms (Brison and Pickett, 1992; Pratt et al., 1992; Douphrate et al., 2006, 2009). Similar figures have been reported for Australia (Fragar et al., 2006) and Denmark (Carstensen et al., 1995).

Being kicked, stepped on, and pushed by the cow are the most frequent animal actions resulting in worker injury (Waller, 1992; Douphrate et al., 2009). Other mechanisms of injury reported are farm workers being caught between a cow and a stall, a cow knocking something onto the person, a cow falling on the person, or the person falling while wrestling the animal (Waller, 1992). Thus, proximity to the animals and handling animals in confined spaces seem to be important risk factors for animal-related injuries.

Fearful and agitated animals are believed to be a major cause of animal-handling injuries (Grandin, 1999). A key factor in the determination of the animal's fear responses to humans is a good human-animal 
relationship (Boivin et al., 2001). Aversive handling, in particular, has been shown to increase cows' fear of humans (Munksgaard et al., 1997). Waiblinger et al. (2002) showed a clear relationship between handler behavior and cow behavior, particularly in terms of avoidance, but also in the number of kick, step, and flinch responses during milking. Whereas negative handling (e.g., punches, slaps, blows) can induce fear of humans, gentle handling can reduce fear responses and thereby make handling safer (Waiblinger et al., 2004). A good human-animal relationship and a low fear level of humans by cows have also been shown to improve animal welfare and productivity (Hemsworth, 2003).

The outcome of an interaction between a human and an animal is dependent on handler behavior, animal behavior, and the environment in which the interaction takes place (Lindahl et al., 2012). Therefore, several studies have suggested that knowledge of safe and effective animal handling techniques and well-designed handling facilities can reduce the incidence of injury (Casey et al., 1997; Langley and Morrow, 2010).

Even if dairy cows are generally tranquil and docile, when situations occur that they perceive or remember as aversive they may become agitated and hazardous to handle. Also, a novel situation can be a strong stressor to the cows (Grandin, 1984). Milking is a daily routine procedure and the cows are used to the routine and the environment. Hoof trimming only occurs a few times a year, but involves new experiences for the cows, restraint, and, possibly, painful treatment. When moved to hoof trimming, a subgroup of cows is commonly separated from the larger group, which can be stressful to the cows. Thus, moving cows to milking is generally a nonstressful situation, whereas moving cows to hoof trimming may be perceived as stressful and aversive to the cows. The aim of the current study was to compare human-animal interactions and handler safety when moving cows to daily milking and moving cows to more rarely occurring hoof trimming.

\section{MATERIALS AND METHODS}

The study was designed as an observational study and 12 commercial dairy farms participated. Farms were identified through agricultural advisors and professional hoof trimmers. All farms had freestall housing and parlor milking and the mean herd size was 158 dairy cows (range $=45-430$ dairy cows). The farms were visited twice, once to observe cows being collected and moved to milking and once to observe cows being collected and moved to hoof trimming. Half the farms were visited for the first time at milking, and the other half for the first at hoof trimming. At each visit, behavioral observations of both handler and cows and cow heart rate recordings were carried out. The visits were performed between April 2012 and February 2013.

The same person on each farm was observed handling the cows on the 2 visits. The participating handlers ranged in age from 23 to $64 \mathrm{yr}$ (mean $36.8 \mathrm{yr}$ ). Eight of the handlers were employees and 4 were farm owners. Three of the handlers were female and 9 were male, and their experience of working with dairy cattle ranged from 3 to $40 \mathrm{yr}$ (mean $15.6 \mathrm{yr}$ ).

When moving cows to milking, the whole group of cows was collected and moved to the holding pen at the same time. Four farms used a transfer alley to the holding pen, 4 farms had the holding pen in direct connection with the freestall, and 4 farms used a section of the freestall as a holding pen. All farms shared the routine of cleaning the cubicles at the same time as collecting cows for milking and of using the hand-held manure scraper to direct the cows.

When moving cows to hoof trimming, cows were collected from the pen individually or in groups of 2 to 12 cows at a time. On some farms the cows were moved to a waiting pen from where a single-file alley led to the trimming chute, whereas others moved the cows straight into a single-file alley. On 6 farms, the trimming chute was placed in a scraped or slatted floor alley in the freestall. On 3 farms, a transfer alley connected with the freestall was used. Two farms used one side of the milking parlor as a transfer alley, with the trimming chute placed in connection with the return alley from the parlor; one farm placed the trimming chute outdoors, just outside the barn door.

\section{Behavioral Observations}

The observations were conducted simultaneously by the same 2 researchers on each farm, one observing the handler and one observing the cows. The observers strove for minimum disturbance by strategic stationing and remaining unobtrusive. The observation started when the handler began to move the cows to milking or hoof trimming (at the same time as the first observation of any of the behaviors in our ethograms) and ended when the cows were in the holding pen waiting to be moved into the parlor to be milked or in the trimming chute (i.e., before the actual milking or hoof trimming started). A stopwatch was used to monitor the duration. The behavior during moving was recorded continuously by counting the number of different behaviors occurring within each minute using all occurrence sampling. Thus, the data included total observation time and observed handler and cow behaviors during each separate minute. More details of other 
recorded variables regarding the handler can be found in our previous paper (Lindahl et al., 2015).

Handler Behavior. The handler's interactions with the cows were recorded as shown in Table 1. Interactions were categorized based on type (acoustic, visual, tactile) and based on the force used (gentle, low, moderate, and forceful). Most behaviors were recorded as either with short or long duration depending on if it was performed continuously during a time period shorter or longer than $5 \mathrm{~s}$. For moving to milking and hoof trimming, respectively, each behavior variable was calculated as the total number of observations of the behavior per total number of cows moved and active minutes of observation. Inactive minutes were excluded (i.e., minutes when the handler interrupted the work of moving the cows for example during waiting time at hoof trimming); this was done to reduce the risk of bias due to difference in waiting time between farms and in the comparison between milking and hoof trimming. Similarly, the time the handler spent cleaning the cubicles was excluded to avoid an effect of the cleaning procedure. The categories of interactions (acoustic, visual and tactile) were calculated as proportion of total number of observations.

Cow Behavior. Only those cows that were within a 2 -m radius of the handler were observed (approximated to 1.5 body lengths of a cow). Their behavior was re- corded according to the definitions presented in Table 2 ; also, a comment section where additional behaviors or events were recorded was available. Each behavior was divided into 2 to 3 different levels (types a, b, and c in Table 2) depending on the intensity or severity of the expression of the behavior. Generally, type a represents the mildest reaction whereas type $\mathrm{c}$ represents the most extreme reaction. Behavioral data were calculated on group level as the total number of observations of the behavior per total number of cows moved and active minutes of observation (i.e., excluding inactive minutes when the cows were not actively handled).

Potentially Dangerous Incidents and Risk Situations. Observed situations and incidents judged to be related to an increased injury risk to the handler were recorded as described in Lindahl et al. (2015). Potentially dangerous incidents were defined as events where physical contact between handler and cow occurred that could have resulted in an injury, for example when the handler was kicked or head-butted. Any additional events relevant to the definition of potentially dangerous incidents were recorded in the comment section. Incidents were recorded as a component of the behavior recording of the cow. Risk situations were defined as slips, trips, and falls by the handler, potentially dangerous incidents (as defined above), and cow behavior indicative of fear or stress [i.e., flight,

Table 1. Ethogram of handler behavior

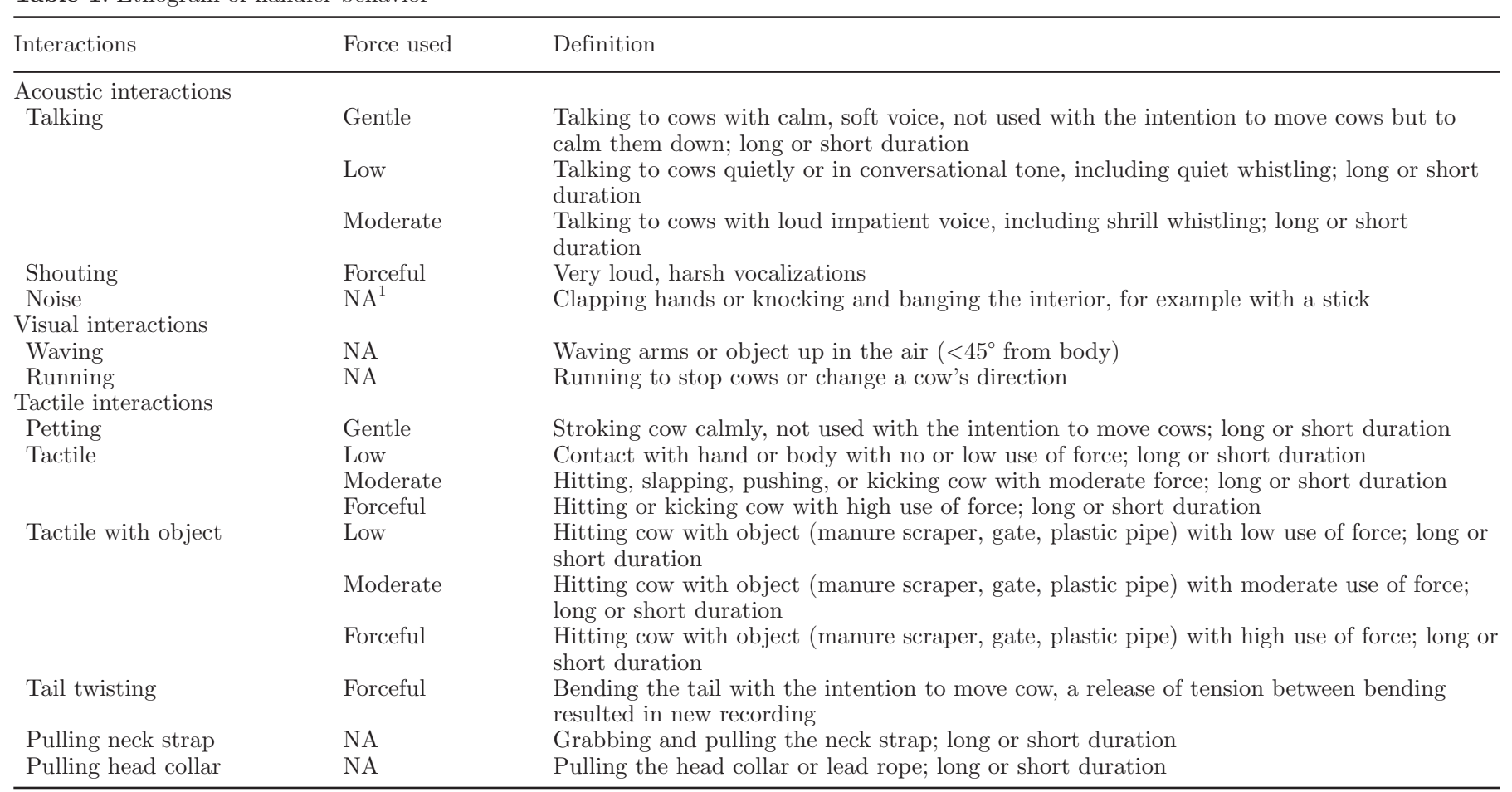

${ }^{1}$ Not applicable. 
resistance, balking (type c), freezing (type c), kicking, head-butting, and forcing]. Slips, trips, and falls by the handler were recorded as a component of the behavior recording of the handler. The number of risk situations and potentially dangerous incidents per minute during the observations were calculated for moving to milking and hoof trimming, respectively.

\section{Heart Rate Measurements}

During each behavioral observation, heart rate was measured on 3 randomly selected cows using Polar Equine CS600X heart rate monitors and Polar Equine Wearlink W.I.N.D transmitter belts (Polar Elektro Oy, Helsinki, Finland). The belts were designed for horses, but were extended to fit the cows. To optimize conductivity, electrode gel (Blågel, Cefar Medical AB, Malmö, Sweden) was applied to the electrodes on the belt. The transmitter belts were attached to the cows approximately $1 \mathrm{~h}$ before observation started, and the average heart rate during an undisturbed period $20 \mathrm{~min}$ before the start of observation was used as a baseline. The deviation for each cow from the baseline was used in the statistical analysis, as the 3 randomly selected cows were not the same at milking and hoof trimming.

At milking, the entire group of cows was collected at the same time; therefore, mean heart rate during the whole observation time (from first interaction until all the cows were in the holding pen) was used, although inactive minutes (e.g., when the handler was cleaning cubicles for a few minutes without interacting with the cows) were excluded. At hoof trimming only a few cows were collected at a time; thus, even if the heart rate measurement lasted a few hours, the actual time the cow was handled only lasted a few minutes. To ensure that the heart rate of each individual cow represented the time when that specific cow was being handled, and so that it was comparable to that collected before milking, mean heart rate for 5 active minutes before the cow entered the trimming chute was used. It is possible the cow was waiting for some part of these 5 min, resulting in an underestimation of the heart rate during moving to hoof trimming.

Table 2. Ethogram of cow behavior

\begin{tabular}{|c|c|}
\hline Behavior & Definition \\
\hline Stopping & $\begin{array}{l}\text { Cow stops a forward movement, appears calm and relaxed } \\
\text { a) Starts to walk without contact by handler } \\
\text { b) Starts to walk directly after contact by handler } \\
\text { c) Does not start to walk despite contact by handler }\end{array}$ \\
\hline Freezing & $\begin{array}{l}\text { Cow stops a forward movement, appears tense or fearful, ears forward, full attention toward item in focus } \\
\text { a) Starts to walk without contact by handler } \\
\text { b) Starts to walk directly after contact by handler } \\
\text { c) Does not start to walk despite contact by handler }\end{array}$ \\
\hline Balking & $\begin{array}{l}\text { Cow backs } \\
\text { a) Backs up on request from handler } \\
\text { b) Balks, stops voluntarily or because of interior or other cow } \\
\text { c) Balks, interrupts because of contact by handler }\end{array}$ \\
\hline Slipping & $\begin{array}{l}\text { Cow's hoof or hooves slide on floor surface } \\
\text { a) All } 4 \text { hooves in contact with floor } \\
\text { b) One or both knees or hocks in contact with floor } \\
\text { c) Slips over to side or belly }\end{array}$ \\
\hline Resisting & $\begin{array}{l}\text { Cow resists moving in the direction the handler wants, tries to pass handler } \\
\text { a) Tries to pass between handler and wall, interior, or other cow, but not completed } \\
\text { b) Passes between handler and wall, interior, or other cow, no contact with handler } \\
\text { c) Passes between handler and wall, interior, or other cow, hits the handler }\end{array}$ \\
\hline Running & $\begin{array}{l}\text { Cow trotting or running } \\
\text { a) Trotting, only a few steps } \\
\text { b) Takes flight, runs away from handler or situation }\end{array}$ \\
\hline Kicking & $\begin{array}{l}\text { Cow kicks with hind leg or legs toward the handler } \\
\text { a) Kicks, no contact with handler } \\
\text { b) Kicks, hits handler }\end{array}$ \\
\hline Head-butting & $\begin{array}{l}\text { Cow butts with the head toward the handler } \\
\text { a) Head-butts, no contact with handler } \\
\text { b) Head-butts, hits handler }\end{array}$ \\
\hline Forcing & Cow tries to force its way through or climb over fitting or structures \\
\hline Vocalizing & Cow vocalizes \\
\hline Defecating & Cow defecates \\
\hline Urinating & Cow urinates \\
\hline Turning & Cow changes direction on prompt by the handler \\
\hline Standing & Cow gets up from lying position on prompt by the handler \\
\hline
\end{tabular}


Table 3. Median proportions of acoustic, tactile, and visual interactions when moving cows to milking and hoof trimming ${ }^{1}$

\begin{tabular}{lcccccc}
\hline & \multicolumn{2}{c}{ Milking } & & \multicolumn{2}{c}{ Hoof trimming } & \\
\cline { 2 - 3 } Interactions & Median & Range & & Median & Range & \\
\hline Acoustic & 0.51 & $0.17-0.69$ & & 0.28 & $0.20-0.46$ & 0.006 \\
Tactile & 0.45 & $0.29-0.76$ & & 0.59 & $0.44-0.72$ & 0.028 \\
Visual & 0.02 & $0.02-0.14$ & & 0.09 & $0.04-0.21$ & 0.005 \\
\hline
\end{tabular}

${ }^{1}$ The total number of interactions per farm was on average 104 (range 11-254) during moving to milking and 634 (range 169-1,123) during moving to hoof trimming $\mathrm{n}=12$.

\section{Statistics}

For statistical analyses of data, the software package SPSS Statistics for Windows, Version 20.0 (IBM Corp., Armonk, NY), was used. The behavior of the handler and cows typically did not show a normal distribution; therefore, nonparametric statistics (related-samples Wilcoxon signed rank test) were used for comparisons of behavioral variables, including risk situations or potentially dangerous incidents between milking and hoof trimming. Spearman correlation coefficient (r) was used to analyze handler behavior in relation to different types of cow behaviors defined as potentially dangerous incidents, such as resisting (type c), kicking (type b), and head-butting (type b).

Differences in cow heart rate during moving to milking and to hoof trimming were analyzed using paired $t$-test (2-tailed), and farm mean values were used for the heart rate data. Due to technical problems, some heart rate measurements were not reliable and were excluded from further analyses; likewise, 2 farms were excluded from the analysis due to missing values for all 3 cows at hoof trimming.

Because the large number of variables resulted in many statistical comparisons, the significance level used in this paper was $P \leq 0.01$ to decrease the risk of type I errors (i.e., incorrectly rejecting the null hypothesis). Only specific comparisons relevant to the aim and research questions of the study were made.

\section{Ethical Considerations}

This study was approved by the Swedish Ethics Committee on Animal Experiments. The research procedures followed the Swedish rules and regulations on use of human subjects in research.

\section{RESULTS}

The average number of cows moved to milking was 80 (range $=43-156)$ and the average time spent moving them was 16 min (range $=3-37 \mathrm{~min}$ ). When moving cows to hoof trimming, the average number of cows moved was 56 (range $=18-156$ ) and the average time spent moving them was $136 \mathrm{~min}$ (range $=44-264 \mathrm{~min}$ ).

\section{Behavior}

Handler Interactions. More interactions per cow were used when cows were being moved to hoof trimming than to milking (average 12.6 and 1.4 interactions/cow respectively; $P<0.001$ ). When moving cows to milking, a higher proportion of acoustic interactions and a lower proportion of visual interactions were used than when moving cows to hoof trimming $(P<0.01$; Table 3). Forceful interactions and gentle interactions were observed on all farms when moving cows to hoof trimming. The most severe category of tactile interaction was forcefully beating a cow repeatedly with an object, and this behavior was observed on 4 farms.

The difference in frequency of handler interactions at milking and hoof trimming are shown in Table 4. The only interaction that occurred with a significantly higher frequency when moving cows to milking compared with hoof trimming was short duration tactile interaction with an object using low force $(P<0.01)$.

The visual interaction used with a higher frequency when moving cows to hoof trimming than when moving them to milking was waving, whereas no significant differences were found for the frequencies of interactions categorized as acoustic. The tactile interactions without an object that were used more frequently during moving cows to hoof trimming were short-duration petting $(P<0.01)$ and long-duration tactile interaction using low force $(P<0.01)$. The tactile interactions with an object that were used more frequently during moving cows to hoof trimming were of short duration with low force $(P<0.01)$ and long duration with moderate force $(P<0.01)$. Tail twisting was also used more frequently when moving cows to hoof trimming $(P<0.01)$.

Cow Behavior. The differences in the number of behaviors per minute and cow when moving cows to milking and hoof trimming are shown in Table 5. Cow behaviors with a higher frequency when moving to 
milking were stopping (type b) and standing. When moving to hoof trimming, the behaviors freezing (types $\mathrm{b}$ and $\mathrm{c}$ ), balking (types b and c), slipping (type a), and resisting (types a and c) had higher frequencies.

Potentially Dangerous Incidents and Risk Situations. The number of potentially dangerous incidents and risk situations per minute was significantly higher when moving cows to hoof trimming than to milking $(P<0.01$ for both incidents and risk situations). When moving cows to milking no potentially dangerous incidents were observed, whereas risk situations (where cows were balking or showing resistance) were only observed on 2 farms. When moving cows to hoof trimming, however, risk situations were observed on all farms and potentially dangerous incidents were observed on all farms except 2 . The frequency of observed risk situations when moving cows to milking ranged from none to 0.05 per minute (median 0.00). Risk situations when moving cows to hoof trimming ranged from 0.6 to 1.7 per min (median 1.0). The frequency of potentially dangerous incidents ranged from none to 0.1 per minute (median 0.03). The most frequently observed potentially dangerous incidents were the handler being kicked, head-butted, or pushed and run over by a resisting cow. Others included being run over, balked into, and crushed between the cow and the interior or wall.

In addition to the routine recordings, several hazardous behaviors by the handler were observed when moving cows to hoof trimming. Some examples were trying to stop a running cow by blocking its path, standing in the waiting pen with agitated cows circulating without an easy escape route, wrapping the lead rope around the hand when leading a cow, and squeezing in between cows or between a cow and the wall or interior fitting.

Table 6 shows correlations between number of handler interactions per minute and cow and number of cow behaviors defined as potentially dangerous incidents per minute and cow when moving cows to hoof trimming. Pulling on the neck strap or halter was positively correlated with the handler being head-butted ( $\mathrm{r}$ $=0.74, P<0.01)$. Use of long-duration forceful tactile interactions with an object (cow being hit repeatedly during $>5 \mathrm{~s}$ ) was positively correlated with the handler being kicked $(\mathrm{r}=0.76, P<0.01)$. Use of short-duration $(<5 \mathrm{~s})$ forceful tactile interactions with an object was positively correlated with the handler being pushed or run over by a resisting cow $(\mathrm{r}=0.72, P<0.01)$. The handler being run over or pushed by a resisting cow was also positively correlated with the handler talking with

Table 4. Handler behaviors per minute per cow when moving cows to milking and hoof trimming (values multiplied by 100 for clarity; $\mathrm{n}=12$ )

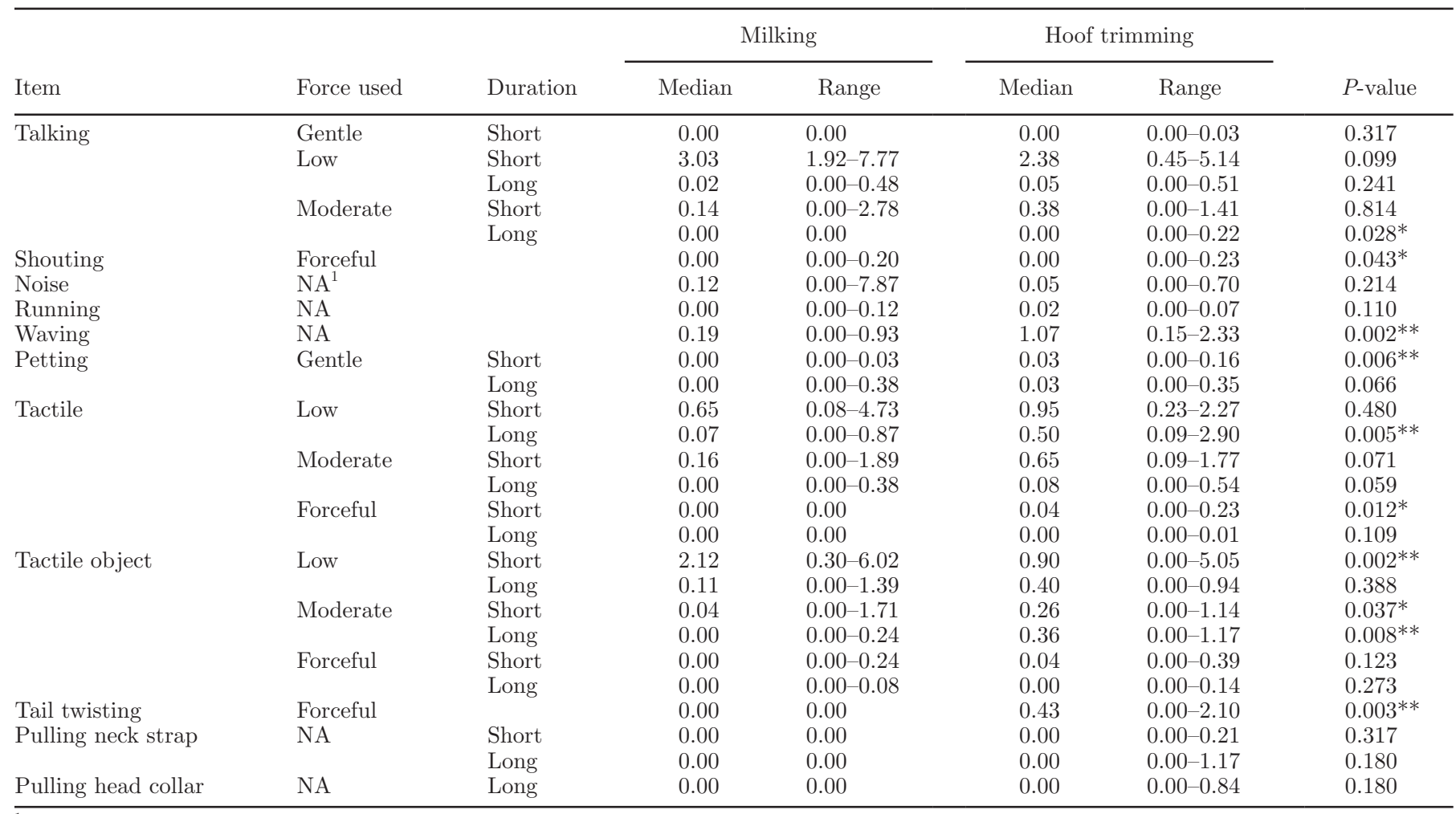

${ }^{1}$ Not applicable.

${ }^{*} P<0.05$; ${ }^{* *} P<0.01$. 
Table 5. Cow behaviors per minute per cow when moving cows to milking and hoof trimming ${ }^{1}$ (values multiplied by 100 for clarity; $\mathrm{n}=12$ )

\begin{tabular}{|c|c|c|c|c|c|}
\hline \multirow[b]{2}{*}{ Behavior } & \multicolumn{2}{|c|}{ Milking } & \multicolumn{2}{|c|}{ Hoof trimming } & \multirow[b]{2}{*}{$P$-value } \\
\hline & Median & Range & Median & Range & \\
\hline Turning & 0.06 & $0.00-0.45$ & 0.28 & $0.00-1.03$ & $0.019^{*}$ \\
\hline \multicolumn{6}{|l|}{ Stopping } \\
\hline Type a) & 0.16 & $0.00-0.63$ & 0.09 & $0.00-0.76$ & 0.239 \\
\hline Type b) & 1.46 & $0.45-5.09$ & 0.58 & $0.02-2.53$ & $0.004^{* *}$ \\
\hline Type c) & 0.15 & $0.00-0.95$ & 0.06 & $0.00-0.82$ & 0.480 \\
\hline Standing & 0.50 & $0.00-2.08$ & 0.04 & $0.00-0.28$ & $0.003^{* *}$ \\
\hline \multicolumn{6}{|l|}{ Freezing } \\
\hline Type a) & 0.00 & 0.00 & 0.01 & $0.00-0.08$ & $0.018^{*}$ \\
\hline Type b) & 0.00 & 0.00 & 0.71 & $0.15-1.02$ & $0.002^{* *}$ \\
\hline Type c) & 0.00 & 0.00 & 1.25 & $0.21-3.91$ & $0.002^{* *}$ \\
\hline \multicolumn{6}{|l|}{ Balking } \\
\hline Type a) & 0.72 & $0.15-1.75$ & 0.45 & $0.14-1.89$ & $0.019^{*}$ \\
\hline Type b) & 0.00 & $0.00-0.06$ & 0.25 & $0.08-0.45$ & $0.002^{* *}$ \\
\hline Type c) & 0.00 & 0.00 & 0.25 & $0.06-1.39$ & $0.002^{* *}$ \\
\hline \multicolumn{6}{|l|}{ Running } \\
\hline Type a) & 0.00 & $0.00-0.12$ & 0.04 & $0.00-0.38$ & $0.016^{*}$ \\
\hline Type b) & 0.00 & 0.00 & 0.00 & $0.00-0.02$ & 0.109 \\
\hline \multicolumn{6}{|l|}{ Slipping } \\
\hline Type a) & 0.02 & $0.00-0.24$ & 0.14 & $0.05-0.51$ & $0.002^{* *}$ \\
\hline Type b) & 0.00 & $0.00-0.04$ & 0.02 & $0.00-0.10$ & $0.021^{*}$ \\
\hline Type c) & 0.00 & 0.00 & 0.00 & $0.00-0.04$ & 0.180 \\
\hline \multicolumn{6}{|l|}{ Resisting } \\
\hline Type a) & 0.00 & $0.00-0.03$ & 0.40 & $0.02-1.17$ & $0.002^{* *}$ \\
\hline Type b) & 0.00 & $0.00-0.04$ & 0.04 & $0.00-0.16$ & $0.015^{*}$ \\
\hline Type c) & 0.00 & 0.00 & 0.03 & $0.00-0.16$ & $0.005^{* *}$ \\
\hline \multicolumn{6}{|l|}{ Kicking } \\
\hline Type a) & 0.00 & 0.00 & 0.00 & $0.00-0.10$ & 0.180 \\
\hline Type b) & 0.00 & 0.00 & 0.00 & $0.00-0.02$ & 0.180 \\
\hline \multicolumn{6}{|c|}{ Head-butting } \\
\hline Type a) & 0.00 & 0.00 & 0.00 & $0.00-0.01$ & 0.317 \\
\hline Type b) & 0.00 & 0.00 & 0.00 & $0.00-0.03$ & 0.317 \\
\hline Forcing & 0.00 & 0.00 & 0.00 & $0.00-0.03$ & 0.180 \\
\hline Vocalizing & 0.00 & 0.00 & 0.01 & $0.00-0.06$ & $0.012^{*}$ \\
\hline Defecating & 0.15 & $0.00-0.48$ & 0.17 & $0.00-0.76$ & 0.347 \\
\hline Urinating & 0.00 & 0.00 & 0.00 & $0.00-0.06$ & 0.180 \\
\hline
\end{tabular}

${ }^{1}$ Types $\mathrm{a}, \mathrm{b}$, and $\mathrm{c}$ represents different levels of the expression of a behavior, from $\mathrm{a}=$ mild reaction to $\mathrm{c}=$ most extreme reaction (see Table 2 for detailed definitions).

${ }^{*} P<0.05 ;{ }^{* *} P<0.01$.

long duration to cows quietly or in a conversational tone $(\mathrm{r}=0.83, P<0.001)$.

\section{Heart Rate}

A larger increase in cow heart rate was observed from baseline during the time cows were being moved to hoof trimming than when they were being moved to milking $(P=0.001$, Figure 1). When being moved to hoof trimming, the individual variation between cows was large both within and between farms. The farm with the highest cow heart rate increase during moving to hoof trimming had a mean increase of 42.2 beats per minute (bpm). This farm also had the highest frequency of freezing behavior (types a and b), balking (type b), and resistance (types b and c). The farm with the lowest cow heart rate increase during moving to hoof trim- ming had a mean of $3.7 \mathrm{bpm}$. The corresponding range when moving cows to milking was -3.0 to $6.4 \mathrm{bpm}$.

\section{DISCUSSION}

We investigated effects on human-cow interactions and safety in a situation that could be perceived as nonstressful or stressful to both cows and handler by observing the collection and moving of cows to milking and hoof trimming. At milking, the cows were commonly moved as a herd and they were quite easily moved using few interactions, consisting mainly of nonforceful tactile interactions, whistling, and talking. The common routine was to clean the cubicles at the same time, and the manure scraper was often gently used to get cows to stand and move. As expected, the cows showed no behavioral signs of stress, fear, or resistance. Cows 
Table 6. Spearman correlation coefficient (r) between handler interactions and incidents per minute per cow when moving cows to hoof trimming, $\mathrm{n}=12$

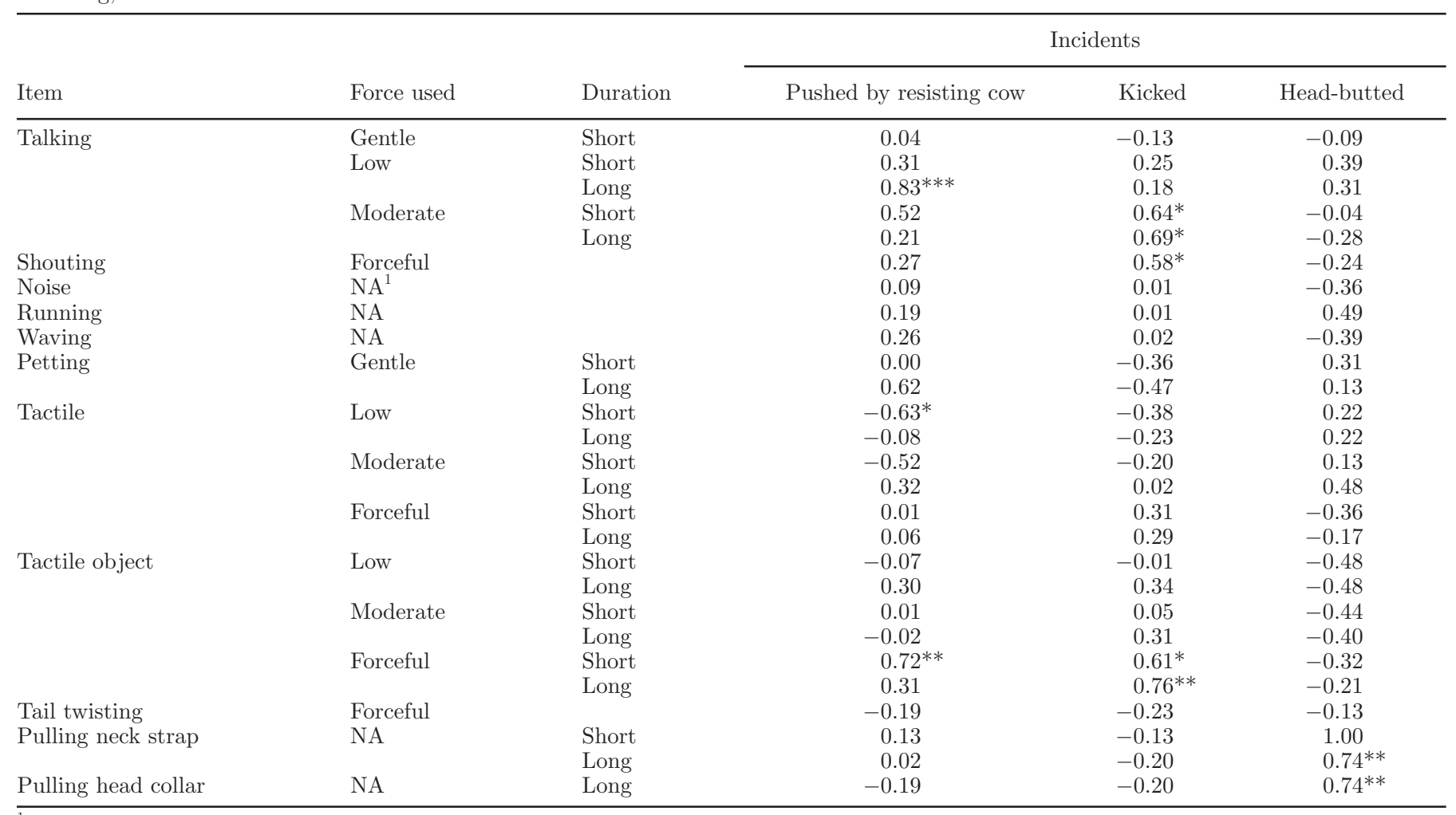

${ }^{1}$ Not applicable.

${ }^{*} P<0.05 ;{ }^{* *} P<0.01 ; * * P<0.001$.

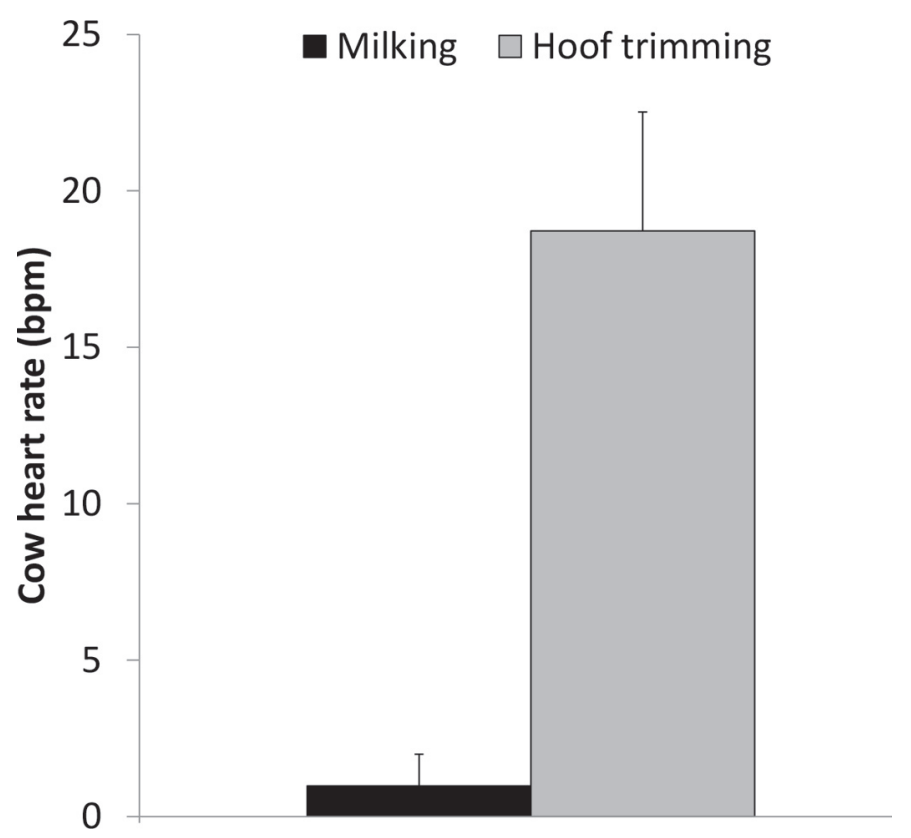

Figure 1. Mean cow heart rate per farm, shown as deviation from the baseline, when cows were being moved to milking and to hoof trimming [beats per minute (bpm); mean $+\mathrm{SE} ; \mathrm{n}=10$ ]. were allowed to move at their own pace and their heart rate only rose slightly from the baseline, indicating little, if any, perceived stress by the cows.

Moving cows to hoof trimming involved more tactile and visual interactions compared with moving cows to milking. Lindahl et al. (2015) also found that a higher proportion of forceful interactions were used when moving cows to hoof trimming. Moving only one or a few cows at a time, resulting in more unwilling cows and more close contact interactions with individual cows, was the probable explanation. Handlers also used more gentle interactions when moving cows to hoof trimming, probably with the intention of calming agitated cows. The potential effectiveness of this is supported by the negative correlation between frequency of risk situations and proportion of gentle interactions found by Lindahl et al. (2015). The cows showed much more behavior indicative of aversion and fear, such as freezing, balking, and resistance, as well as a higher heart rate increases during moving to hoof trimming than to milking. These results confirm that the cows perceived moving to hoof trimming to be a more stressful situation than moving to milking. 
An unpublished study (C. Lindahl) indicated that cows recognize hoof trimming as a specific event because of various signals in the stable when setting up the trimming chute, handling facility, and so on (i.e., explicit sounds, smells and visual influences). Consequently, cows show specific reactions and behaviors in relation to hoof trimming compared with any unexpected herding event.

The injury risk to which the handler was exposed during handling was much higher during moving to the more aversive hoof trimming. From having no potentially dangerous incidents and very few risk situations when moving cows to milking, this increased to an average of 0.95 risk situations and 0.03 potentially dangerous incidents per minute when moving cows to hoof trimming. This means that during each hour spent actively moving cows to hoof trimming, the handler on average had 1.8 physical contacts with a cow that could have resulted in injury (e.g., head-butted, kicked). In light of these results, it is not surprising that statistics show such high injury rates related to animal handling in dairy farming.

Some interactions could be specifically related to potentially dangerous incidents. Pulling the neck strap or halter was positively correlated with the handler being head-butted, which is probably a consequence of them being in a very exposed position close to the cow's head while it is struggling to get away. The frequency of potentially dangerous incidents has previously been found to be positively correlated with the time the handler spends in the area around the cow, where he or she could be hit by a cow's head or hind legs (Lindahl et al., 2015). Thus, avoiding these areas around the cow during handling is probably an effective strategy to increase safety for the handler. Forceful tactile interactions with an object were positively correlated with incidents where the handler was kicked, run over, or pushed by a resisting cow; these reactions by the cows can be a fear response. A few handlers occasionally used an unacceptable amount of force, with excessive beating of cows in sensitive areas such as the nose ridge, even though this handling was not very efficient, as cows often reacted by freezing, a fear response (Davis, 1992). Previous studies have shown that rough and aversive handling of dairy cows can make them more fearful and difficult to handle (Breuer et al., 2000; Hemsworth et al., 2000; Boivin et al., 2003; Breuer et al., 2003).

No correlations were found between tail twisting or forceful hitting without an object and potentially dangerous incidents, even though these were also categorized as forceful interactions and may therefore induce fear. Pajor et al. (2000) compared different treatments that are often used when moving cows and found that tail twisting and hitting cows on the rump with an open hand were not perceived as more aversive than no handling. In a subsequent study, where cows were allowed to choose between treatments, they showed no preference for no treatment over tail twisting (Pajor et al., 2003), thereby supporting the conclusion that tail twisting is not aversive. However, such a conclusion probably depends on the force used, and in our observations it was not possible to distinguish between forceful and gentle tail twisting. However, if the cows did experience it as strongly aversive, a correlation to kicking incidents would have been expected, especially as tail twisting is difficult to perform without standing in the risk zone of being hit.

Shouting may not appear to be a very forceful interaction, but Pajor et al. (2000, 2003) concluded that shouting may be perceived by cows as being as aversive as the use of an electric prod. Waynert et al. (1999) found that sounds of humans shouting as well as metal clanging evoked responses indicative of fear in beef cattle based on elevated heart rate and increased movement, and shouting in particular appeared to be more alarming. In the present study, a tendency $(P$ $<0.05$ ) was noted for a positive correlation between shouting, talking loudly, and incidents where the handler was kicked by a cow. Furthermore, talking to cows quietly or in a conversational tone for a long duration was positively correlated with incidents where the cow was resisting and running over or pushing the handler. Even though the causal relationship is not clear, it seems that quiet handling with minimum talking, in particular avoiding loud talking and shouting, should be recommended.

When interpreting the results presented in our paper, one should bear in mind that the study was conducted on a small number of farms and, even if we limited the number of comparisons and raised the significance level, we cannot exclude that some results are significant by chance. On the other hand, the observations were carried out on commercial farms, so the recommendation arising from our study should have increased practical relevance. In the remaining part of this discussion we present some of these recommendations.

Aversive procedures are impossible to avoid completely in modern dairy production, and how these procedures are performed is not just an animal welfare issue, but also a safety issue for the handlers. As stated in previous studies (Hemsworth et al., 2000; Boivin et al., 2003; Breuer et al., 2003) and supported by the current study, dairy cattle should be handled calmly and without the use of forceful interactions. The cattlehandling technique most reported in the literature is the principle of flight zone and point of balance described by Grandin (1999). Tirloni et al. (2013) found that extensively raised cows handled in a calm and 
quiet manner using these principles appeared calmer when restrained than cows handled as usual during the operation (e.g., by yelling, kicking, and using electric prods and sticks). More extensive scientific evidence is needed to confirm the effectiveness of these handling principles on intensively raised dairy cattle, especially during aversive management procedures.

Another possible solution is to prepare the cows better to cope with aversive procedures by training them, thereby reducing their level of fear by positive reinforcement, as has been used to train zoo and laboratory animals to comply with unpleasant procedures (Young and Cipreste, 2004). Training and familiarization of dairy heifers to the milking procedure and environment has been found to have positive effects during the first week of lactation on behavioral responses (Bremner, 1997) and distress experienced (Sutherland and Huddart, 2012). Training cattle to accept aversive procedures, for example to willingly enter a trimming chute, would improve efficiency, animal welfare, and, not least, handler safety. This is already an active area of research with companion animals, especially dogs (Hiby et al., 2004; Rooney and Cowan, 2011; Fukuzawa and Hayashi, 2013).

Another relevant factor, although not studied in the current work, is to provide a safe environment for cows and handler (e.g., nonslip flooring) and handling facilities that enable good cow flow. Using the cows' natural behavior has also been suggested as a way to make handling easier (Grandin, 1980; e.g., using the cows' instinct to move as a herd and to walk in a line following the cow in front).

In conclusion, moving cows to hoof trimming resulted in higher frequencies of behaviors indicating fear, more forceful interactions, and increased injury risks to the handler than moving cows to milking. Improving potentially stressful handling procedures (e.g., by better animal-handling practices and preparation of cows to cope with such procedures) can increase handler safety, animal welfare, ease of handling, and efficiency.

\section{ACKNOWLEDGMENTS}

This work was partially supported by funds from the SLO Foundation (Stockholm, Sweden), administered by the Royal Swedish Academy of Agriculture and Forestry (Stockholm, Sweden), and the Swedish University of Agricultural Sciences (Alnarp). We are most grateful to the farmers and handlers for their kind participation and hospitality. We thank Sofia Åström (Swedish University of Agricultural Sciences, Uppsala), who was deeply involved in data collection. We also acknowledge the valuable statistical advice of Jan-Eric
Englund, Department of Biosystems and Technology, Swedish University of Agricultural Sciences.

\section{REFERENCES}

Boivin, X., B. J. Lensink, and I. Veissier. 2001. The farmer and the animal: A double mirror. Human-animal relationship: Stockmanship and housing in organic livestock systems. Pages 7-15 in Proc. of the Third NAHWOA Workshop, Clermont-Ferrand, France. University of Reading, Reading, UK.

Boivin, X., J. Lensink, C. Tallet, and I. Veissier. 2003. Stockmanship and farm animal welfare. Anim. Welf. 12:479-492.

Bremner, K. J. 1997. Behaviour of dairy heifers during adaption to milking. Proc. N.Z. Soc. Anim. Prod. 57:105-108.

Breuer, K., P. H. Hemsworth, J. L. Barnett, L. R. Matthews, and G. J. Coleman. 2000. Behavioural response to humans and the productivity of commercial dairy cows. Appl. Anim. Behav. Sci. 66:273-288.

Breuer, K., P. H. Hemsworth, and G. J. Coleman. 2003. The efffect of positive or negative handling on the behavioural and physiological responses of nonlactating heifers. Appl. Anim. Behav. Sci. 84:3-22.

Brison, R. J., and C. W. L. Pickett. 1992. Nonfatal farm injuries on 117 eastern Ontario beef and dairy farms: A one-year study. Am. J. Ind. Med. 21:623-636.

Carstensen, O., J. Lauritsen, and K. Rasmussen. 1995. The WestJutland study on prevention of farm accidents, phase 1: A study of work specific factors in 257 hospital-treated agricultural injuries. J. Agric. Saf. Health 1:231-239.

Casey, G. M., A. M. Grant, D. S. Roerig, J. Boyd, M. Hill, M. London, K. H. Gelberg, E. Hallman, and J. Pollock. 1997. Farm worker injuries associated with cows. AAOHN J. 45:446-450.

Davis, M. 1992. The role of the amygdala in fear and anxiety. Annu Rev. Neurosci. 15:353-375.

Douphrate, D. I., J. C. Rosecrance, L. Stallones, S. J. Reynolds, and D. P. Gilkey. 2009. Livestock-handling injuries in agriculture: an analysis of Colorado workers' compensation data. Am. J. Ind. Med. 52:391-407.

Douphrate, D. I., J. C. Rosecrance, and G. Wahl. 2006. Workers' compensation experience of Colorado agriculture workers, 2000-2004. Am. J. Ind. Med. 49:900-910.

Douphrate, D. I., L. Stallones, C. Lunner Kolstrup, M. W. Nonnenmann, S. Pinzke, G. R. Hagevoort, P. Lundqvist, M. Jakob, H. Xiang, L. Xue, P. Jarvie, S. A. McCurdy, S. Reed, and T. Lower. 2013. Work-related injuries and fatalities on dairy farm operations - A global perspective. J. Agromedicine 18:256-264.

Fragar, L. J., K. Pollock, C. Morton, and L. Day. 2006. Occupational Health and Safety Risk in the Australian Dairy Industry. The Facts 2006. Australian Centre for Agricultural Health and Safety, Univ. Sydney, Moree, Australia.

Fukuzawa, M., and N. Hayashi. 2013. Comparison of 3 different reinforcements of learning in dogs (Canis familiaris). J. Vet. Behav. $8: 221-224$

Grandin, T. 1980. Observations of cattle behavior applied to the design of cattle-handling facilities. Appl. Anim. Ethol. 6:19-31.

Grandin, T. 1984. Reduce stress of handling to improve productivity of livestock. Vet. Med. Small Anim. Clin. 79:827-831.

Grandin, T. 1999. Safe handling of large animals. Occup. Med. 14:195212.

Hemsworth, P. H. 2003. Human-animal interactions in livestock production. Appl. Anim. Behav. Sci. 81:185-198.

Hemsworth, P. H., G. J. Coleman, J. L. Barnett, and S. Borg. 2000. Relationships between human-animal interactions and productivity of commercial dairy cows. J. Anim. Sci. 78:2821-2831.

Hiby, E. F., N. J. Rooney, and J. W. S. Bradshaw. 2004. Dog training methods: Their use, effectiveness and interaction with behaviour and welfare. Anim. Welf. 13:63-69.

Langley, R. L., and W. E. M. Morrow. 2010. Livestock handlingMinimizing worker injuries. J. Agromedicine 15:226-235. 
Lindahl, C., P. Lundqvist, A. Lindahl, and A. Norberg. 2012. Swedish dairy farmers' perceptions of animal-related injuries. J. Agromedicine 17:364-376.

Lindahl, C., S. Pinzke, L. J. Keeling, and P. Lundqvist. 2015. The effect of stress, attitudes and behavior on safety during animal handling in Swedish dairy farming. J. Agric. Saf. Health 21:13-34.

Munksgaard, L., A. M. de Passillé, J. Rushen, K. Thodberg, and M. B. Jensen. 1997. Discrimination of people by dairy cows based on handling. J. Dairy Sci. 80:1106-1112.

Pajor, E. A., J. Rushen, and A. M. B. de Passillé. 2000. Aversion learning techniques to evaluate dairy cattle handling practices. Appl. Anim. Behav. Sci. 69:89-102.

Pajor, E. A., J. Rushen, and A. M. B. de Passillé. 2003. Dairy cattle's choice of handling treatments in a Y-maze. Appl. Anim. Behav. Sci. 80:93-107.

Pinzke, S., and P. Lundqvist. 2007. Occupational accidents in Swedish agriculture. Agric. Eng. Res. 13:159-165.

Pratt, D. S., L. H. Marvel, D. Darrow, L. Stallones, J. J. May, and P. Jenkins. 1992. The dangers of dairy farming-The injury experience of 600 workers followed for 2 years. Am. J. Ind. Med. 21:637-650.

Rooney, N. J., and S. Cowan. 2011. Training methods and owner-dog interactions: Links with dog behaviour and learning ability. Appl. Anim. Behav. Sci. 132:169-177.
Sutherland, M. A., and F. J. Huddart. 2012. The effect of training first-lactation heifers to the milking parlor on the behavioral reactivity to humans and the physiological and behavioral responses to milking and productivity. J. Dairy Sci. 95:6983-6993.

Tirloni, R. R., F. A. Rocha, F. J. Lourenco, and L. R. Martins. 2013. Influence of low-stress handling on reactivity score and pregnancy rate during fixed-time artificial insemination in Nellore cows. Rev. Bras. Zootec. 42:471-474.

Waiblinger, S., C. Menke, and G. Coleman. 2002. The relationship between attitudes, personal characteristics and behaviour of stockpeople and subsequent behaviour and production of dairy cows. Appl. Anim. Behav. Sci. 79:195-219.

Waiblinger, S., C. Menke, J. Korff, and A. Bucher. 2004. Previous handling and gentle interactions affect behaviour and heart rate of dairy cows during a veterinary procedure. Appl. Anim. Behav. Sci. 85:31-42.

Waller, J. A. 1992. Injuries to farmers and farm families in a dairy state. J. Occup. Med. 34:414-421.

Waynert, D. F., J. M. Stookey, K. S. Schwartzkopf-Genswein, J. M. Watts, and C. S. Waltz. 1999. The response of beef cattle to noise during handling. Appl. Anim. Behav. Sci. 62:27-42.

Young, R. J., and C. F. Cipreste. 2004. Applying animal learning theory: Training captive animals to comply with veterinary and husbandry procedures. Anim. Welf. 13:225-232. 